\title{
BADN announce new dental nurse awards
}

The British Association of Dental Nurses (BADN) has revisited its Outstanding Contribution to Dental Nursing Award and developed four new Awards:<smiles>C1CC1</smiles>
The BADN Award for Outstanding Service to Dental Nursing Professional

Practice

This award is for someone who has made an outstanding contribution to the development and/or support of the dental nursing profession, with minimum ten years in profession.

\section{The BADN Award for Exceptional Commitment as a Dental Nurse Student}

This award is for someone who has made an exceptional commitment to their own progression and personal/professional development whilst studying for a registerable dental nursing qualification, a post-registration or extended duties qualification, or a higher academic qualification (eg BSc etc)

\section{nt

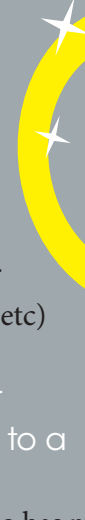

This award is for someone who has made an exceptional contribution to one of the dental charities (which must be registered with the Charities Commission)

\section{The BADN Award for Exceptional Contribution to a UK Community Oral Healthcare Project}

This award is for someone who has made an exceptional contribution to one of their local UK Community Oral Healthcare projects.

Nominations for the Awards are invited from anyone working in dentistry; nominees must be BADN members and, with the exception of the Student Award, GDC registered dental nurses.

All nominations must be on the official form and be received by the Chief Executive by close of business on 31 July at pam@badn.org.uk. Nominees and nominators will be informed by the end of September and the Awards presented at the Closing Ceremony of the National Dental Nursing Conference in Blackpool on Saturday 17

November 2018.

Full details of the nomination criteria and the nomination form are available on the BADN website www.badn.org.uk/ badn-awards.

\section{'Keep Smiling'} campaign

\section{lamelhed}

\section{for elderly}

On 19 April the Relatives \& Residents Association (R\&RA) launched a 'Keep Smiling' campaign to highlight the importance of dental health.

At the Association's AGM, R\&RA

Chair Judy Downey emphasised what a crucial area of care dental health is, and that it matters not only for good health, but for all aspects of well-being and selfesteem: 'Older people today are more likely to keep their natural teeth than ever before. They have higher expectations of a healthy mouth and looking good.

'As the handbook points out, it's hard to keep smiling when you've got toothache or a problem with your mouth. As a person's ability to care for their teeth and dentures gets harder so does the general health of their mouth unless they have the support of those who care for them.'

The 'Keep Smiling' campaign builds on the R\&RA's successful Keys to Care programme, supporting care workers in their day-to-day work. The publication is available to download at: http://www. relres.org/wp-content/uploads/KeepSmiling.pdf. It explains and shows care workers and carers useful skills, tools and techniques, as well as dental care in action in different care settings. There is an associated video in production.

\section{Keep Smiling}

\section{ARE YOU READY FOR NATIONAL Sm}

National Smile Month, the UK's largest and longest-running oral health campaign, kicks off this year on 14 May and runs until 14 June 2018.

National Smile Month will communicate the importance of a healthy mouth and support people from all around the UK to adopt an effective oral health routine.

The campaign, organised by the Oral Health Foundation (OHF), will deliver three key messages for better oral health:

- Brush your teeth last thing at night and at least one other time during the day, with a fluoride toothpaste

- Cut down on how much and how often you have sugary foods and drinks

- Visit the dentist regularly - as often as they recommend.

At the campaign launch, held in the British Academy on 8 May 2018, the OHF's President, Professor Liz Kay MBE, spoke about the Oral Health Foundation's leading role in driving health policy, not only in the UK but also around Europe.

To get involved and importantly to order your smileys, visit www.smilemonth.org

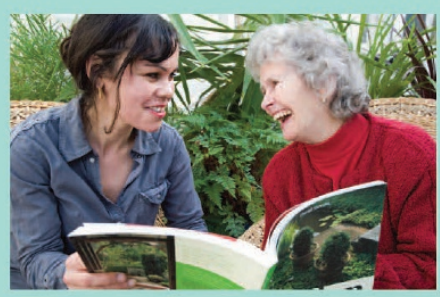

Mouth \& teeth care for older people 